\title{
Reversibility of antibiotic resistance on country level - how long does it take? (Letter)
}

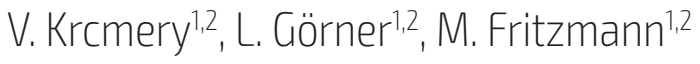

Original Articles

${ }^{1}$ St. Elizabeth University $\mathrm{PhD}$ and MSc program, Bratislava

${ }^{2}$ Health Post, Nickelsdorf, Austria

\section{Correspondence to:}

St. Elizabeth University, MSc and PhD program, Dept. of Public Health, Nám. 1. Mája č. 1, 81000 Bratislava, Slovakia

Mary Immaculata SEU Tropic program, Nairobi, Kenya

Submitted: 17.6.2016

Revised: 12.8.2016

Accepted: 1.9 .2016

\section{Reviewers:}

D. Kimuli

Manager, Hope for Sick and Poor, Utawala, Nairobi, Kenya

K. Zoller

Slovak Tropical Institute St. Elizabeth Univ. Field Hospital, Bratislava, Slovakia

\section{Key words:}

Antibiotic, Reversibility, ATB, Antibiotic policies.

CSWHI 2016; 7(3): 14-15; DOI 10.22359/cswhi_7_3_03 @ 2016 Clinical Social Work and Health Intervention

In a recent paper and similar editorial published in the April 2016 Issue of The Lancet, I.M. Gould and Timothy Lawes [2] and on similar issues of Medical Review A. Shahum et al (6) data or reversibility of ATB resistance are rare. They discussed the reversibility of antibiotic (ATB) resistance on country levels in dynamic scale in 2000 and also in 2014. This dynamic data opens a question - how long does it take that the susceptibility to return to previous levels. There is very little published on reversibility of antibiotic resistance on country levels, in contrast to numerous reports on hospital levels and also in specific patients groups [3]. The question how long does it take to repair the negative consequences of ATB over prescription was addressed in a few studies from less populated Scandinavian countries, e.g. Finland [4]. Gould's and Lawes's paper is one of the very few longitudinal comparisons of consumption data within recent years, and are available due to the results from the European Study of Antibiotic Consumption (ESAC) [5]. Again, apart from France, all other 5 countries which showed decline of ATB consumption were "small" countries with centralized antibiotic policies (Slovakia, Slovenia, Lithuania, Estonia and Portugal).

According to our experience from the leading Antibiotic Committee of the Ministry of Health of the Slovak Republic, unacceptably high consumption was managed with at least 3 administrative and financial mechanisms: 
- deleting of specific ATB classes temporary from National ATB formulary

- increasing of co-payment in reimbursement as a national strategy,

- prescription limits, temporary shifting ATB to Category B (results of susceptibility required) or Category $\mathrm{C}$ (written agreement from the Regional or Hospital Antibiotic Committees).

Slovakia which succeeded to control ATB consumption also decreased or stabilized Penicillin resistance in pneumococci and ampicillin resistance in $\mathrm{H}$. influenza, as well as MRSA. It is easier to have restrictive centralized antibiotic policy in small countries and with centralized health policies, than in large countries, affected by the migrant crisis in the last 2 years (UK, France, Italy and Greece). Hallsworth's et al [6] study is an example is that a behavioral approach not limited to one hospital (710) or department can be successful in ATB prescription control also in large countries.

\section{References}

1. KRCMERY V, KALAVSKY E: Antibiotic Resistance in "ATB free" environment. In Neuroendocrinology Letter, 2007, 28, 83, p. 33-34.

2. GOULD IM, LAWES T: Antibiotic stewardship: prescribing social norms The Lancet
Vol. 387, No. 10029, p1699-1701, 23 April 2016

3. KRCMERY V, TRUPL J: Bacteraemia due to penicillin-resistant Streptococcus viridans in cancer patients, before and after prophylaxis with penicillin The Lancet 1995 Nov 18; 346(8986):1362-3.

4. SEPPÄLÄ H: The Effect of Changes in the Consumption of Macrolide Antibiotics on Erythromycin Resistance in Group A Streptococci in Finland: NE J Med 1997; 337: 441-44

5. GOOSENS H: Outpatient antibiotic use in Europe and association with resistance: a cross-national database study. The Lancet 2005 Feb 12-18; 365(9459): 579-87.

6. HALLSWORTH: Provision of social norm feedback to high prescribers of antibiotics in general practice: a pragmatic national randomized controlled trial. The Lancet Volume 387, No. 10029, p1743-1752, 23 April 2016

7. SILHAROVA B, SUVADA J, FRANEKOVA M, NOGE A, MIKOLASOVA G: $M a-$ laria in hyperendemic region, Neuroendcrinology Letters 34, 2013, s1 38-43

8. SUVADA J, CZARNECKI P, TOMANEK P, JANKECHOVA M et al. Social Pathology in Health Care. WSM. Warszav, 2015, pp. 455. 